\title{
Medical Interpreters in Outpatient Practice
}

\author{
Barb Jacobs, MEd ${ }^{1}$ \\ Anne M. Ryan, JD2,3 \\ Katberine S. Henrichs ${ }^{2,4}$ \\ Barry D. Weiss, $M^{3,5}$ \\ 'Language Interpreter Center, Alaska Insti- \\ tute for Justice, Anchorage, Alaska
}

${ }^{2}$ Tucson Family Advocacy Program, Medical Legal Partnership for Health, Tucson,

Arizona

${ }^{3}$ Department of Family and Community Medicine, University of Arizona College of Medicine, Tucson, Arizona

${ }^{4}$ University of Arizona James E. Rogers College of Law, Tucson, Arizona

${ }^{5}$ Department of Health Sciences, University of Alaska, Anchorage, Alaska

Conflicts of interest: authors report none.

\section{CORRESPONDING AUTHOR}

Barry D. Weiss, MD

Department of Family and Community Medicine

University of Arizona College of Medicine 1450 North Cherry

Tucson, AZ 85718

bdweiss@u.arizona.edu

\begin{abstract}
This article provides an overview of the federal requirements related to providing interpreter services for non-English-speaking patients in outpatient practice. Antidiscrimination provisions in federal law require health programs and clinicians receiving federal financial assistance to take reasonable steps to provide meaningful access to individuals with limited English proficiency who are eligible for or likely to be encountered in their health programs or activities. Federal financial assistance includes grants, contracts, loans, tax credits and subsidies, as well as payments through Medicaid, the Children's Health Insurance Program, and most Medicare programs. The only exception is providers whose only federal assistance is through Medicare Part B, an exception that applies to a very small percentage of practicing physicians. All required language assistance services must be free and provided by qualified translators and interpreters. Interpreters must meet specified qualifications and ideally be certified. Although the cost of interpreter services can be considerable, ranging from $\$ 45-\$ 150 /$ hour for in-person interpreters, to $\$ 1.25-\$ 3.00 /$ minute for telephone interpreters, and $\$ 1.95-\$ 3.49 /$ minute for video remote interpreting, it may be reimbursed or covered by a patient's Medicaid or other federally funded medical insurance. Failure to use qualified interpreters can have serious negative consequences for both practitioners and patients. In one study, 1 of every 40 malpractice claims were related, all or in part, to failure to provide appropriate interpreter services. Most importantly, however, the use of qualified interpreters results in better and more efficient patient care.
\end{abstract}

Ann Fam Med 2018;16:70-76. https://doi.org/10.1370/afm.2154.

\section{MEDICAL INTERPRETERS IN OUTPATIENT PRACTICE}

U nless they are traveling and become ill in a non-English-speaking country, it is likely that most English-speaking clinicians in the United States have never had the experience of explaining their illness symptoms to a health professional who didn't speak their language. But, for millions of people with limited English proficiency (LEP) living in the United States, this is an everyday occurrence.

The United States is changing demographically. According to the most recent US Census, from 2010 to 2014, about 62 million people (born in the United States or another country) spoke a language other than English at home. ${ }^{1}$ About $41 \%$ of these individuals ( 25 million people) have LEP, defined in the census as individuals older than 5 years who speak English "less than very well."1 The Census Bureau projects a similar percentage on into 2020. ${ }^{2}$

Medical professionals who work with LEP patients should rely on trained and, ideally, certified, medical interpreters to give them the best comprehension of what a patient is saying. Having a patient try to get by with limited English, using untrained bilingual staff or family members, or having clinicians use their limited language ability (for example, high school Spanish) to communicate in the patient's language, can have dire consequences both for the patient and the clinician. Consider this wellknown real-life example:

On bis initial medical bistory, a Spanish-speaking boy aged 18 years, of Cuban descent, presented with abnormal mental status complaining of "intoxicado." An untrained interpreter 
understood this to mean that the boy was intoxicated - though in the Cuban dialect, the boy was actually saying that be was "nauseated." He received care for a drug overdose attributed to substance abuse but developed paraplegia, subsequently found to be due to a ruptured intracranial aneurysm. The case led to malpractice lawsuit with a $\$ 71$ million award to the plaintiff. 3,4

\section{Is Providing Interpreter Services a Requirement?}

Discrimination on the basis of national origin or other protected categories in programs or activities receiving federal financial assistance has long been prohibited in the United States. To assure compliance with Title VI of the 1964 Civil Rights Act, ${ }^{5}$ Executive Order 13166, ${ }^{6}$ issued in 2000, required federal agencies to develop systems to improve access to their programs and services for persons with LEP, defined as those "whose primary language for communication is not English" and who have "a limited ability to read, write, speak, or understand English." ${ }^{17}$ In 2003 the Department of Health and Human Services (HHS) published guidance about how to meet the provisions of the aforementioned executive order by providing LEP individuals with meaningful access to federal health care programs (HHS LEP Guidance). ${ }^{8,9}$ That guidance continues to be used today. In addition, the prohibitions against discrimination in health care programs were further addressed and codified in HHS regulations implementing Section 1557 of the Affordable Care Act (ACA). ${ }^{10,11}$

Consistent with HHS LEP Guidance, the regulations require all covered health care programs and providers to take "reasonable steps to provide meaningful access to each individual with limited English proficiency eligible to be served or likely to be encountered in its health programs and activities."12 Required language assistance services must be free to patients, accurate and timely, protect patient confidentiality, and be provided by qualified interpreters. ${ }^{13}$

Entities covered by these antidiscrimination provisions include those who meet any of the following criteria: (a) operate a "health program or activity," any part of which receives "federal financial assistance" from HHS (eg, hospitals, health clinics, state Medicaid agencies, health insurance issuers, nursing homes, physician practices, etc) $;$ (b) are administered by HHS (eg, Medicare programs, Medicaid programs, the Children's Health Insurance Program [CHIP]); or most recently (c) were established under the Patient Protection and Affordable Care Act (ACA), such as state-based and federally facilitated Health Insurance Marketplaces. ${ }^{7}$ Pertinent to item (a), operating a health program or activity includes provision or administration of healthrelated services as well as health-related insurance coverage. If any part of the health program or activity of the covered entity receives federal financial assistance from HHS, then all of its programs and activities are subject to these antidiscrimination provisions.

The important point for outpatient practices is that receiving federal financial assistance includes submitting claims and receiving payments from federal government programs like Medicaid, most Medicare programs, or CHIP. ${ }^{14,15}$ The one exception to this rule is if the only federal financial assistance a clinician or practice receives is Medicare Part B. ${ }^{16}$ The Department of Health and Human Services has noted, however, that "almost all practicing physicians in the United States...accept some form of Federal remuneration or reimbursement apart from Medicare Part B" and therefore are subject to these requirements. ${ }^{16-18}$

Determinations of whether covered entities, including physicians and practices that receive federal financial assistance, have taken the required reasonable steps to provide meaningful access to LEP individuals must be made on a case-by-case basis. Factors that will be considered include the "nature and importance of the health program or activity and the particular communication at issue ${ }^{\prime \prime 19}$ and other relevant factors including whether the entity has "developed and implemented an effective written language access plan appropriate to its particular circumstances." 20

Although development and implementation of a language access plan continues to be voluntary, it is a key component in evaluating compliance. Other relevant factors include: (1) the prevalence of LEP individuals in the population eligible to be served or likely to be encountered, (2) the frequency with which they are encountered in the practice, (3) the cost of providing language assistance services, and (4) whether the practice has availed itself of all available opportunities to lower costs. ${ }^{21-23}$

\section{How to Meet the Requirements?}

When entities are required to provide interpretation for LEP individuals, they must use the services of "qualified" medical interpreters. Unfortunately, when an interpreter appears in clinic or hospital settings to assist during a clinician-patient encounter, most clinicians assume the interpreter is qualified to interpret. But, that's not always the case. ${ }^{24}$

A qualified interpreter for an individual with LEP is one who "(1) adheres to generally accepted interpreter ethics principles, including client confidentiality; (2) has demonstrated proficiency in speaking and understanding both spoken English and at least one other spoken language; and (3) is able to interpret effectively, accurately, and impartially, both receptively and expressly, to and from such language(s) and English, using any necessary specialized vocabulary, terminology and phraseology."25 
Federal regulations and guidance do not require interpreters to be licensed or certified. Use of certified interpreters is required in some states, ${ }_{1}^{26}$ however, and HHS considers certification helpful to establish competency. ${ }^{27}$

Certified medical interpreters have a high level of fluency in 2 or more languages, have been trained in the ethics and role of a medical interpreter, study medical terminology, and can facilitate the flow of a patientclinician medical visit-including making clinic visits shorter than when telephonic or uncertified in-person interpreters are used ${ }^{28}$ In contrast to "trained" interpreters, certified interpreters have participated in a formal medical interpreter education program and have passed written and oral examinations in medical interpreting. Just like medical professionals, they have a code of professional standards and ethics among which includes accuracy, confidentiality, and impartiality.

Currently there are only 2 national organizations in the United States that provide formal certification of medical interpreters: The National Board of Certification for Medical Interpreters ${ }^{29}$ and the Certification Commission for Healthcare Interpreters. ${ }^{30}$ Whenever possible, clinicians and health systems should seek to use the services of interpreters who are certified by these organizations.

It is not appropriate to rely on health care staff to interpret unless they are "qualified bilingual/multilingual staff" — defined as individuals who meet the requirements listed in Table $1 .{ }^{31}$ Practices and health systems covered by the regulations cannot require patients to provide their own interpreters. ${ }^{32}$ The use of minor children accompanying a patient to serve as interpreters is also prohibited except in emergency situations involving "an imminent threat to the safety or welfare" of the patient when no qualified interpreter is available.$^{33}$ In addition, adults accompanying the patient cannot be used as interpreters absent emergency conditions or where the patient specifically requests that the accompanying individual interprets and "reliance on that adult for such assistance is appropriate under the circumstances." ${ }^{134}$

Finally, covered entities are also required to post notices of nondiscrimination and include "taglines" in appropriate languages on specified documents and signs that alert individuals with LEP to the availability of language assistance services. ${ }^{35}$ Examples of a sample notice of nondiscrimination and taglines in over 60 languages are available free on the HHS website. ${ }^{36}$

\section{What Are the Options and How Much Do They Cost?}

Physicians in small practices often cite cost as a barrier to using trained interpreters ${ }^{37}$ and indeed, costs can be considerable - though they vary from state to state. ${ }^{38,39}$ They also vary depending on whether a practice uses in-person face-to-face interpreters, telephonic interpreters, or video remote interpreting.

\section{In-Person Interpreters}

If using a face-to-face interpreter provided through a language translation service, costs are generally in the range of $\$ 45$ - $\$ 150$ per hour, often with a minimum time requirement (eg, 2-hour minimum). ${ }^{39}$ Costs can vary, however, depending on the language involved. For example, in an area where many Spanish-language interpreters are available, the cost is often lower than in areas where few are available. The costs for an interpreter of languages that are rarely spoken, in contrast, can be more. Costs for an independent interpreter who is not affiliated with a language service provider can also be more.

\section{Telephonic Interpreters}

Many medical providers use telephonic language services to provide immediate language assistance, and this approach costs less than face-to-face interpreters. Telephonic interpreters are paid by the minute, but there can be a set-up charge along with volume minimums or monthly minimums that vary between

\section{Table 1. Definition of Qualified Interpreters ${ }^{25,31}$}

\begin{tabular}{|c|c|}
\hline $\begin{array}{l}\text { Qualified Interpreter for an Individual With Limited } \\
\text { English Proficiency }\end{array}$ & Qualified Bilingual/Multilingual Staff \\
\hline $\begin{array}{l}\text { An individual who, via a remote interpreting service or } \\
\text { on-site presence: } \\
\text { Adheres to generally accepted interpreter ethics principles, } \\
\text { including client confidentiality }\end{array}$ & $\begin{array}{l}\text { A member of a covered entity's workforce who is designated by the covered } \\
\text { entity to provide oral language assistance as part of the individual's cur- } \\
\text { rent, assigned job responsibilities and who has demonstrated to the cov- } \\
\text { ered entity that he or she: }\end{array}$ \\
\hline $\begin{array}{l}\text { Has demonstrated proficiency in speaking and understanding } \\
\text { both spoken English and at least one other spoken language }\end{array}$ & $\begin{array}{l}\text { Is proficient in speaking and understanding both spoken English and at } \\
\text { least one other spoken language, including any necessary specialized } \\
\text { vocabulary, terminology, and phraseology }\end{array}$ \\
\hline $\begin{array}{l}\text { Is able to interpret effectively, accurately, and impar- } \\
\text { tially, both receptively and expressly, to and from such } \\
\text { language(s) and English, using any necessary specialized } \\
\text { vocabulary and phraseology }\end{array}$ & $\begin{array}{l}\text { Is able to effectively, accurately, and impartially communicate directly with } \\
\text { individuals with limited English proficiency in their primary languages }\end{array}$ \\
\hline
\end{tabular}


services. A typical cost is in the range $\$ 1.25-\$ 3.00$ per minute, ${ }^{39}$ varying between companies and varying with the time of day and language.

While telephonic interpreting is convenient, less costly, and in some situations the only available option (particularly in practices with patients speaking multiple languages), it can sometimes be suboptimal..$^{40}$ Problems cited with telephonic interpretation include inadequate clarity of sound, the inability of the interpreter to respond to visual cues from the patient and clinician, and cultural barriers in which some patients are not comfortable speaking with an unknown voice. ${ }^{41,42} \mathrm{~A}$ face-to-face interpreter, rather than telephonic interpreting, is particularly important in mental health settings, for communicating with patients who are hardof-hearing, for patient education that includes visual components, and when communicating with children. ${ }^{43}$

\section{Video Remote Interpreting}

Video remote interpreting (VRI) is a video telecommunication service that uses devices such as web cameras or videophones to provide language services via a remote/off-site interpreter. Video remote interpreting has long been used for sign language interpreter services. Similar to telephonic interpreters, VRI can be used when qualified or certified interpreters are not available for face-to-face interpretation. The Department of Health and Human Services has developed standards for use of VRI that are listed in Table 2. ${ }^{44}$

Costs of VRI involve expenses for equipment and for the interpreter service. Costs for equipment can vary widely, depending on whether a practice simply uses a laptop or desktop computer or a more sophisticated setup using cameras, speakers, and microphones. Commonly cited costs for VRI interpreter services can range from as little as $\$ 1.95$ per minute to as much as $\$ 3.49$ per minute, sometimes with a minimum number of minutes (eg, 15 minutes) per session. ${ }^{45,46}$

\section{How Can the Cost be Managed?}

In some cases the cost of interpreter services will be reimbursed or covered by a patient's federally funded medical insurance. Medicaid and CHIP programs in at least 14 states and the District of Columbia (Table 3) will reimburse providers or language service agencies for the cost of interpreter services involved in a covered patient's care. ${ }^{47-50}$ In those states in particular, cost should not be an obstacle to clinicians providing interpreters for Medicaid and CHIP patients, though clinicians in some states must cover the up-front costs and then seek reimbursement from the state program. Using billing code T-1013 along with the CPT code that is appropriate for the clinical encounter is one option for claiming reimbursement for these services. ${ }^{51}$
Table 2. Health and Human Services' Standards for Video Remote Interpreting

Video remote interpreting (VRI) shall be provided with a qualified interpreter for an individual with limited English proficiency. When using VRI, the health program or activity shall provide:

Real-time, full-motion video and audio over a dedicated highspeed, wide-bandwidth video connection or wireless connection that delivers high-quality video images that do not produce lags, choppy, blurry, or grainy images, or irregular pauses in communication

A sharply delineated image that is large enough to display the interpreter's face and the participating patient's face regardless of the patient's body position

A clear, audible transmission of voices

Adequate training to users of the technology and other involved individuals so that they can quickly and efficiently set up and operate the video remote interpreting ${ }^{44}$

\section{Table 3. States in Which Medicaid/CHIP Programs Will Reimburse Health Care or Language Service Providers for the Cost of Interpreter Services ${ }^{48}$}

\begin{tabular}{ll}
\hline District of Columbia & New Hampshire \\
Hawaii & New York \\
lowa & Utah \\
Idaho & Vermont \\
Kansas & Virginia \\
Maine & Washington \\
Minnesota & Wyoming \\
Montana & \\
\hline
\end{tabular}

Although not specifically required to do so, states are also permitted to "claim federal matching funds for the costs of....oral interpretation as administrative expenses or as medical assistance-related expense."47

In addition to reimbursement, some states have adopted other systems to keep the cost of interpretation from falling on individual health care providers. For example, Arizona's Medicaid program requires each contracted managed care organization to provide free interpretation services. ${ }^{52}$ By calling the patient's contracted plan, individual health care providers can then obtain free telephonic interpretation services on an as-needed basis at no cost to the provider or patient.

Additionally, other states and providers have centralized telephonic language services to reduce costs. ${ }^{53}$ The Department of Health and Human Services encourages covered entities to work together and with professional associations to develop the most cost-effective delivery programs for language assistance services, ${ }^{54}$ suggesting approaches such as use of communication technology and sharing language assistance materials and services (eg, telephonic interpreter services could be shared between Medicaid programs in different states). ${ }^{54}$

Finally, HHS has reminded qualified health insurance issuers of their obligation as a condition of certi- 
fication to implement a quality improvement strategy that "provides increased reimbursement or other incentives for the implementation of activities to reduce ... health care disparities, including through the use of language services." 55 The Department of Health and Human Services "encourage(s) health insurance issuers to structure their health plan payment structures to consider health providers' expenses in providing language assistant services." 55

\section{Are the Costs Worth It?}

Regardless of the federal and state requirements for language assistance or whether federally funded state programs provide reimbursement, providing appropriate interpretation services is a basic and key component of good patient care for individuals with LEP. Indeed, both the Institute of Medicine and the Joint Commission recognize the need for effective communication as an important aspect of high-quality care. ${ }^{56,57}$

Besides enhancing the quality of care and avoiding poor health outcomes for patients, there are potential negative consequences for health care providers that do not provide appropriate language assistance services. As noted earlier in the case example, malpractice lawsuits can result from adverse patient outcomes due to incorrect language interpretation. In fact, a report in 2010 evaluating 1,373 malpractice claims from 4 states found that 1 of every 40 claims were related, all or in part, to failure to provide appropriate language interpreter services. ${ }^{58}$ Some cases resulted in multi-million dollar malpractice settlements. ${ }^{59}$ Covered health care providers may also be subject to enforcement actions for failure to provide appropriate interpreter services. ${ }^{60,61}$

\section{Working With An Interpreter}

Many health care systems and medical practices provide training to staff on working with an interpreter. Resources are also available in the medical literature ${ }^{62}$ and through free online continuing medical education programs. ${ }^{63}$ This type of training will give clinicians and staff information on the ethics and role of a trained medical interpreter, how to make the clinical encounter go smoothly to provide the best care to patients, and other tips for working with interpreters.

Furthermore, in addition to helping ensure compliance with federal requirements, having a comprehensive "language access plan" will help a practice provide excellent care to LEP patients in ways other than just providing interpreter services. A language access plan contains policies and procedures to guide staff in providing meaningful access to services for individuals with LEP. Guidance and language access plan models have long been available from HHS and other sources. ${ }^{64,65}$ More information on developing a plan that fits the needs of your practice can be found at http://www.lep.gov.

\section{FINAL COMMENT}

Providing the best care to patients, complying with legal requirements, and developing and implementing a language access plan will assist clinicians in helping their patients stay safe and healthy. A language access plan that involves professional medical interpreters will provide better health outcomes, ethical patient care, improved patient satisfaction, and reduce costly repeat visits by patients who don't understand what clinicians are asking or telling them about their medical problems. ${ }^{66,67}$

To read or post commentaries in response to this article, see it online at http://www. AnnFamMed.org/content/16/1/70.

Key words: language interpreters; patient-physician communication; health literacy

Submitted May 14, 2017; submitted, revised, June 30, 2017; accepted July 24, 2017.

\section{References}

1. United States Census Bureau. Detailed languages spoken at home and ability to speak English for the population 5 years and over: 2009-2013. https://www.census.gov/data/tables/2013/demo/20092013-lang-tables.html. Published Oct 2015. Accessed Feb 2017.

2. Ortman JM, Shin HB. Language projections: 2010 to 2020. https:// www.census.gov/hhes/socdemo/language/data/acs/Ortman_Shin_ ASA2011_paper.pdf. Published Aug 2011. Accessed Apr 2017.

3. $\mathrm{Ku}$ L, Flores $\mathrm{G}$. Pay now or pay later: providing interpreter services in health care. Health Aff. 2005;24:435-444.

4. Harsham P. A misinterpreted word worth $\$ 71$ million. Med Econ. 1984;12:289-292.

5. United States Department of Justice. Title VI of the Civil Rights Act of 196442 USC §2000D ET SEQ; Overview of Title VI of the Civil Rights Act of 1964. https://www.justice.gov/crt/fcs/TitleVI-Overview. Accessed Apr 2017.

6. US Department of Justice. Executive Order 13166: Improving access to services for persons with limited English proficiency. 65 Fed Reg at 50123. https://www.justice.gov/sites/default/files/crt/ legacy/2010/12/14/eolep.pdf. Published Aug 16, 2000. Accessed Apr 2017.

7. Nondiscrimination in Health Programs and Activities, Definitions. 81 Fed Reg at 31466-67; 45 CFR § 92.4. https://www.federalregister.gov/documents/2016/05/18/2016-11458/nondiscrimination-inhealth-programs-and-activities\#page-31466. Accessed Apr 2017.

8. US Department of Health and Human Services. Guidance to Federal Financial Assistance Recipients Regarding Title VI Prohibition Against National Origin Discrimination Affecting Limited English Proficient Persons. https://www.hhs.gov/civil-rights/for-individuals/ special-topics/limited-english-proficiency/guidance-federal-financialassistance-recipients-title-VI/index.html. Accessed Apr 2017.

9. Guidance to Federal Financial Assistance Recipients Regarding Title VI Prohibition Against National Origin Discrimination Affecting Limited English Proficient Persons. https://www.gpo.gov/fdsys/pkg/ FR-2003-08-08/pdf/03-20179.pdf. 68 Fed Reg at 47311-47323. Published Aug 8, 2003. Accessed Apr 2017. 
10. US Department of Health and Human Services. Nondiscrimination in Health Programs or Activities. 81 Fed Reg at 31376, 45 CFR Part 92. https://www.gpo.gov/fdsys/pkg/FR-2016-05-18/pdf/2016-11458. pdf. Accessed Apr 2017.

11. The Public Health and Welfare Chapter 157 - Quality, Affordable Health Care for All Americans, Subchapter VI - Miscellaneous Provisions. 42 USC 157(VI), Section 18116: Nondiscrimination. https:// www.gpo.gov/fdsys/pkg/USCODE-2010-title42/html/usCODE-2010title42-chap157-subchapVI-sec18116.htm. Published 2010. Accessed Apr 2017.

12. Nondiscrimination in Health Programs and Activities, Meaningful Access for Individuals with Limited English Proficiency. https:// www.federalregister.gov/d/2016-11458/page-31470. 81 Fed Reg at 31470; 45 CFR § 92.201(a). Accessed April 2017.

13. Nondiscrimination in Health Programs and Activities, Meaningful Access for Individuals with Limited English Proficiency, Language Assistance Services Requirements. https://www.federalregister. gov/d/2016-11458/page-31470. 81 Fed Reg at 31470; 45 CFR § 92.201(c),(d). Accessed Apr 2017.

14. Nondiscrimination in Health Programs and Activities, Federal Financial Assistance. https://www.federalregister.gov/d/2016-11458/ page-31383. 81 Fed Reg at 31383-86. Published May 18, 2016. Accessed Apr 2017.

15. US Department of Health and Human Services. Guidance to Federal Financial Assistance Recipients Regarding Title VI Prohibition Against National Origin Discrimination Affecting Limited English Proficient Persons. https://www.gpo.gov/fdsys/pkg/FR-2003-08-08/ pdf/03-20179.pdf. 68 Fed Reg at 47313. Published Aug 2003. Accessed Apr 2017.

16. Nondiscrimination in Health Programs and Activities, Federal Financial Assistance. https://www.federalregister.gov/d/2016-11458/ page-31383. 81 Fed Reg at 31383, 31385. Published May 18, 2016. Accessed Apr 2017.

17. US Department of Health and Human Services. What qualifies as "federal financial assistance" for purposes of civil rights complaints handled by OCR? http://www.hhs.gov/civil-rights/for-individuals/ faqs/what-qualifies-as-federal-financial-assistance/301/index.html. Updated Nov 19, 2015. Accessed Apr 2017.

18. Nondiscrimination in Health Programs and Activities, Regulatory Impact Analysis, Examples of covered entities with a health program or activity, any part of which receives federal financial assistance from the department. https://www.federalregister.gov/d/201611458/page-31446. 81 Fed Reg at 31446; 45 CFR $\S$ 92.4. Accessed Apr 2017.

19. Nondiscrimination in Health Programs and Activities, Alternative approaches. https://www.federalregister.gov/d/2016-11458/page31413. 81 Fed Reg at 31413-16; 45 CFR § 92.201(b)(1). Accessed Apr 2017.

20. Nondiscrimination in Health Programs and Activities, Alternative approaches. https://www.federalregister.gov/d/2016-11458/page31415. 81 Fed Reg at 31415; 45 CFR § 92.201(b)(2). Accessed Apr 2017.

21. Federal Coordination and Compliance Section, Civil Rights Division, uS Department of Justice. Language Access Assessment and Planning Tool for Federally Conducted and Federally Assisted Programs. https://www.lep.gov/resources/2011_Language_Access_Assessment_ and_Planning_Tool.pdf. Published May 2011. Accessed Apr 2017.

22. Limited English Proficiency, A Federal Interagency Website. LEP.gov. https://www.lep.gov/faqs/faqs.html\#OneQ7. Accessed Apr 2017.

23. Nondiscrimination in Health Programs and Activities, Alternative approaches. https://www.federalregister.gov/d/2016-11458/page31416. 81 Fed Reg at 31416; 45 CFR § 92.201(b)(2). Accessed Apr 2017.

24. Flores $G$, Abreu M, Barone CP, Bachur R, Lin H, Errors of medical interpretation and their potential clinical consequences: a comparison of professional versus ad hoc versus no interpreters. Ann Emerg Med. 2012; 60:545-55.
25. Nondiscrimination in Health Programs and Activities, Qualified interpreter for an individual with limited English proficiency. $81 \mathrm{Fed}$ Reg at 31468; 45 CFR § 92.4. Accessed Apr 2017.

26. Washington State Department of Social and Health Services, Financial Services Administration. Language Testing and Certification Program. https://www.dshs.wa.gov/fsa/language-testing-andcertification-program. Published 2017. Accessed Apr 2017.

27. Guidance to Federal Financial Assistance Recipients, Selecting language assistance services, Considerations relating to competency of interpreters and translators. https://www.gpo.gov/fdsys/pkg/ FR-2003-08-08/pdf/03-20179.pdf. 68 Fed Reg at 47316. Published Aug 8, 2003. Accessed Apr 2017.

28. Fagan M, Diaz J, Reinert SE, Sciamanna CN, Fagan DM. Impact of interpretation method on clinic visit length. J Gen Intern Med. 2003;18:643-638.

29. The National Board of Certification for Medical Interpreters. http:// www.certifiedmedicalinterpreters.org/. Accessed Apr 2017.

30. Certification Commission for Healthcare Interpreters. http://www. cchicertification.org/. Accessed Apr 2017.

31. Nondiscrimination in Health Programs and Activities, Qualified bilingual/multilingual staff. https://www.federalregister.gov/ documents/2016/05/18/2016-11458/nondiscrimination-in-healthprograms-and-activities\#page-31467. 81 Fed Reg at 31467, 31470; 45 CFR § 92.4. Accessed Apr 2017.

32. Nondiscrimination in Health Programs and Activities, Restricted use of certain persons to interpret or facilitate communication. https://www.federalregister.gov/documents/2016/05/18/2016-11458/ nondiscrimination-in-health-programs-and-activities\#page-31470. 81 Fed Reg at 31470; 45 CFR § 92.201(e)(1). Accessed Apr 2017.

33. Nondiscrimination in Health Programs and Activities, Restricted use of certain persons to interpret or facilitate communication. https://www.federalregister.gov/documents/2016/05/18/2016-11458/ nondiscrimination-in-health-programs-and-activities\#page-31470. 81 Fed Reg at 31470; 45 CFR § 92.201(e)(3). Accessed Apr 2017.

34. Nondiscrimination in Health Programs and Activities, Restricted use of certain persons to interpret or facilitate communication. https://www.federalregister.gov/documents/2016/05/18/2016-11458/ nondiscrimination-in-health-programs-and-activities\#page-31470. 81 Fed. Reg. at 31470; 45 CFR § 92.201(e)(2). Accessed Apr 2017.

35. Nondiscrimination in Health Programs and Activities, Notice requirement. https://www.federalregister.gov/documents/2016/05/18/2016-11458/nondiscrimination-in-healthprograms-and-activities\#page-31469. 81 Fed Reg at 31469; 45 CFR $\S$ 92.8. Accessed Apr 2017.

36. US Department of Health and Human Services. Translated Resources for Covered Entities. https://www.hhs.gov/civilrights/for-individuals/section-1557/translated-resources/index. html?language =es. Accessed Apr 2017.

37. Gadon M, Balch Gl, Jacobs EA. Caring for patients with limited English proficiency: the perspectives of small group practitioners. J Gen Intern Med. 2007;22(Suppl 2):341-346.

38. National Center for State Courts. Language Access Programs by State. http://www.ncsc.org/Services-and-Experts/Areas-of-expertise/ Language-access/Resources-for-Program-Managers/LAP-Map/Map. aspx. Accessed Apr 2017.

39. American Medical News. Picking your best option for patient interpretation services. Published Aug 5, 2013. Accessed Apr 2017.

40. Rush R. Lost in translation. N Eng J Med. 2016; 374:407-409.

41. Saint-Louis L, Friedman E, Chiasson E, Quessa A, Novaes F. Testing New Technologies in Medical Interpreting. Somerville, MA: Cambridge Health Alliance; 2003. http://www.challiance.org/Resource.ashx?sn = CommunityAffairstnthndbk. Accessed Jun 2017.

42. National Association of Judiciary Interpreters and Translators. NAJIT Position Paper: Telephone Interpreting in Legal Settings. https:// najit.org/wp-content/uploads/2016/09/Telephone-Interpreting-1.pdf. Published Feb 27, 2009. Accessed Jun 2017. 
43. Kelly N. Telephone interpreting in health care settings: some commonly asked questions. American Translators Association Chronicle. http://www.atanet.org/chronicle/feature_article_june2007.php. Published Jun 2007. Accessed Apr 2017.

44. Nondiscrimination in Health Programs and Activities, Video remote interpreting services. https://www.federalregister.gov/ documents/2016/05/18/2016-11458/nondiscrimination-in-healthprograms-and-activities\#page-31470. 81 Fed Reg at 31470-31471; 45 CFR § 92.201(f). Accessed Apr 2017.

45. Interpreters Unlimited. Video remote interpreting rates. http://interpretersunlimited.com/pricing/video-remote-interpretation/. Accessed Jun 2017.

46. Deaf and Hard of Hearing in Government. Video remote interpreting (VRI) fact sheet. http://www.dhhig.org/Resources/Documents/ VRI\%20Fact\%20Sheet\%20Text\%20(MJ).pdf. Accessed Jun 2017.

47. Department of Health and Human Services. Increased federal matching funds for translation and interpretation services under Medicaid and CHIP. https://www.medicaid.gov/federal-policyguidance/downloads/sho10007.pdf. Published Jul 1, 2010. Accessed Apr 2017.

48. Youdelman M. Medicaid and CHIP reimbursement models for language services. National Health Law Program. http://www. healthlaw.org/publications/browse-all-publications/Medicaid-CHIPReimbursement-Models-Language-Services\#.WKxpTxLyvox . Published Feb 7, 2017. Accessed Apr 2017.

49. Youdelman M. Medicaid and CHIP reimbursement models for language services (2009 update). National Health Law Program. http://www.healthlaw.org/component/jsfsubmit/showAttachment?tm $\mathrm{pl}=$ rawsid $=00 \mathrm{Pd000000BzyadEAB}$. Published 2009. Accessed Apr 2017.

50. How can states get Federal funds to help pay for language services for Medicaid and CHIP enrollees (Revised January 2010)? National Health Law Program. http://www.healthlaw.org/component/jsfsubmit/showAttachment?tmpl = rawsid =00Pd0000006EH2XEAW. Published 2010. Accessed Apr 2017.

51. Medicaid Administrative Claiming. Translation and interpretation services. Medicaid.gov. https://www.medicaid.gov/medicaid/ financing-and-reimbursement/admin-claiming/translation/index. html. Accessed Apr 2017.

52. Arizona Health Care Cost Containment System (AHCCCS). Contractor Operations Manual, Chapter 400 - Operations. 405 - Cultural Competency, Language Access Plan, and Family/Patient Centered Care. https://www. azahcccs.gov/shared/downloads/acom/acom. pdf. Revised Feb 2017. Accessed Dec 2017.

53. Washington State Health Care Authority. Billers and providers; interpreter services. http://www.hca.wa.gov/billers-providers/ programs-and-services/interpreter-services. Accessed Apr 2017.

54. Nondiscrimination in Health Programs and Activities, Alternative Approaches. https://www.federalregister.gov/d/2016-11458/page31413. 81 Fed Reg at 31413-14. Accessed Apr 2017.

55. Nondiscrimination in Health Programs and Activities, Alternative Approaches. https://www.federalregister.gov/d/2016-11458/page31414. 81 Fed Reg at 31414. Accessed Apr 2017.
56. Wilson-Stronks A, Lee K, Cordero C, Kopp A, Galvez E. One Size Does Not Fit All: Meeting the Needs of Diverse Populations. Oakbrook Terrace, IL: The Joint Commission; 2008. http://www. jointcommission.org/PatientSafety/HLC/one_size_meeting_need_of_ diverse_populations.htm. Accessed Apr 2017.

57. Smedley B, Stith A, Nelson A, eds. Unequal Treatment: Confronting Racial and Ethnic Disparities in Health Care. Washington, DC: The National Academies Press; 2002. https://www.nap.edu/ catalog/10260/unequal-treatment-confronting-racial-and-ethnicdisparities-in-health-care. Accessed Dec 2017.

58. Quan K, Lynch J, National Health Law Program, School of Public Health University of California Berkeley. The high costs of language barriers in medical malpractice. Berkeley, CA: University of California; 2010. http://www.pacificinterpreters.com/docs/resources/highcosts-of-language-barriers-in-malpractice_nhelp.pdf. Accessed Apr 2017.

59. Price-Wise G. Language, culture, and medical tragedy: The case of Willie Ramirez. Health Affairs Blog. http://healthaffairs.org/ blog/2008/11/19/language-culture-and-medical-tragedy-the-case-ofwillie-ramirez/. Published Nov 2008. Accessed Apr 2017.

60. US Department of Health and Human Services, Office of Civil Rights. Enforcement success stories involving persons with limited English proficiency: summary of selected OCR compliance reviews and complaint investigations. https://www.hhs.gov/civil-rights/ for-providers/compliance-enforcement/examples/limited-englishproficiency/index.html. Accessed Apr 2017.

61. National Association of Community Health Centers. Compliance with section 1557 of the Affordable Care Act: requirements related to individuals with limited English proficiency. http://www.nachc. org/wp-content/uploads/2015/10/12.16-Section-1557-Compliancefact-sheet.pdf. Accessed Dec 2017.

62. Juckeett $G$, Unger K. Appropriate use of medical interpreters. Am Fam Physician. 2014; 90:476-480.

63. US Department of Health and Human Services. A Physician's Practical Guide to Culturally Competent Care. https://cccm.thinkculturalhealth.hhs.gov/. Accessed Dec 2017.

64. US Department of Justice, Civil Rights Division. Language Access Assessment and Planning Tool for Federally Conducted and Federally Assisted Programs. https://www.lep.gov/resources/2011_Language_Access_Assessment_and_Planning_Tool.pdf. Published May 2011. Accessed Dec 2017.

65. Wasserman M, Renfrew MR, Green AR, et al. Identifying and preventing medical errors in patients with limited English proficiency: key findings and tools for the field. J Healthc Qual. 2014;36(3):5-16.

66. Karliner LS, Jacobs EA, Chen AH, Mutha S. Do professional interpreters improve clinical care for patients with limited English proficiency? A systematic review of the literature. Health Serv Res. 2007:42:727-754.

67. Betancourt JR, Renfrew MR, Green AR, et al. Improving patient safety systems for patients with limited English proficiency: a guide for hospitals. Rockville, MD: Agency for Healthcare Research and Quality; 2012. AHRQ Publication No. 12-0041. http://www.ahrq. gov/sites/default/files/publications/files/lepguide.pdf. Revised Sep 2012. Accessed Apr 2017. 